\title{
Genetic characterization and zoonotic potential of Blastocystis from wild animals in Sichuan Wolong National Natural Reserve, Southwest China
}

\author{
Shanyu Chen ${ }^{1, a}$, Wanyu Meng ${ }^{1, a}$, Ziyao Zhou ${ }^{1, a}$, Lei Deng ${ }^{1, a}$, Xiaogang Shi ${ }^{2}$, Yijun Chai ${ }^{1}$, Haifeng Liu ${ }^{1}$, \\ Yuehong Cheng ${ }^{2}$, Zhijun Zhong ${ }^{1}$, Hualin $\mathrm{Fu}^{1}$, Liuhong Shen ${ }^{1}$, Kun Zhang ${ }^{1}$, Tingmei $\mathrm{He}^{2, *}$, \\ and Guangneng Peng ${ }^{1, *}$ \\ ${ }^{1}$ Key Laboratory of Animal Disease and Human Health of Sichuan Province, College of Veterinary Medicine, \\ Sichuan Agricultural University, Chengdu 611130, Sichuan, PR China \\ ${ }^{2}$ Sichuan Wolong National Natural Reserve Administration, Aba 623006, Sichuan, PR China
}

Received 30 July 2021, Accepted 13 October 2021, Published online 27 October 2021

\begin{abstract}
Blastocystis is a prevalent eukaryotic parasite that has been identified in a wide range of hosts. Several species are considered potential sources of Blastocystis infection in humans, but little is known about the prevalence of Blastocystis in wild animals. In this study, the prevalence and subtypes of Blastocystis were investigated to assess the zoonotic potential of wild animals in Sichuan Wolong National Natural Reserve. A total of 300 fecal samples were collected from 27 wildlife species in three areas of the Reserve. The subtype (ST), genetic characteristics, and prevalence of Blastocystis were determined by PCR amplification of part ( $600 \mathrm{bp})$ of the SSU rRNA gene. Thirty fecal samples (10.0\%) were Blastocystis-positive. The highest prevalence of Blastocystis was found in Yinchanggou $(18.3 \%)$, with significantly less found in Niutoushan $(7.5 \%)$ and Genda $(5.5 \%)(p<0.05)$. No significant differences were associated with different orders of animals in prevalence, which may be because of the small number of positive samples obtained. Sequence analysis showed five subtypes (ST1, ST3, ST5, ST13, and ST14), with ST13 and ST14 being predominant (33\% each), followed by ST1 (20\%). This is the first molecular investigation of Blastocystis infection in the wild animals of southwestern China. Subtypes ST1, ST3, ST5, and ST14 have previously been identified in humans, suggesting that wild animals may be potential reservoirs of Blastocystis for humans.
\end{abstract}

Key words: Blastocystis, Wild animals, Prevalence, Subtypes, China.

\begin{abstract}
Résumé - Caractérisation génétique et potentiel zoonotique de Blastocystis provenant d'animaux sauvages dans la réserve naturelle nationale du Sichuan Wolong, sud-ouest de la Chine. Blastocystis est un parasite eucaryote répandu qui a été identifié dans un large éventail d'hôtes. Plusieurs espèces sont considérées comme des sources potentielles d'infection par Blastocystis chez l'homme, mais on sait peu de choses sur la prévalence de Blastocystis chez les animaux sauvages. Dans cette étude, la prévalence et les sous-types de Blastocystis ont été étudiés pour évaluer le potentiel zoonotique des animaux sauvages dans la réserve naturelle nationale du Sichuan Wolong. Au total, 300 échantillons de matières fécales ont été prélevés de 27 espèces de la faune dans trois zones de la réserve. Le sous-type (ST), les caractéristiques génétiques et la prévalence de Blastocystis ont été déterminés par amplification PCR d'une partie ( 600 pb) du gène 18S de l'ARNr. Trente échantillons fécaux (10,0\%) étaient positifs pour Blastocystis. La prévalence la plus élevée de Blastocystis a été trouvée à Yinchanggou (18,3\%), avec une prévalence significativement moindre à Niutoushan $(7,5 \%)$ et à Genda $(5,5 \%)(p<0,05)$. Aucune différence significative de prévalence n'était associée à différents ordres d'animaux, ce qui peut être dû au petit nombre d'échantillons positifs obtenus. L'analyse des séquences a montré cinq sous-types (ST1, ST3, ST5, ST13 et ST14), et ST13 et ST14 étant prédominants (33\% chacun), suivis de ST1 (20\%). Il s'agit de la première étude moléculaire de l'infection à Blastocystis chez les animaux sauvages du sud-ouest de la Chine. Les sous-types ST1, ST3, ST5 et ST14 ont déjà été identifiés chez l'homme, suggérant que les animaux sauvages pourraient être des réservoirs potentiels de Blastocystis pour l'homme.
\end{abstract}

\footnotetext{
*Corresponding authors: pgn. sicau@163.com;248109505@qq. com
}

${ }^{\text {a }}$ These authors contributed equally to this work. 


\section{Introduction}

The enteric parasite Blastocystis (classified as a Stramenopile) is the most common protist found in humans [34]. The primary mode of transmission is through Blastocystiscontaminated water and food via the fecal-oral route [13]. There is strong evidence to suggest that some human infections may be caused by the zoonotic transmission of Blastocystis [25, 36]. The pathogenicity of Blastocystis remains controversial, with studies associating it with various gastrointestinal disorders such as inflammatory bowel disease (IBD) and irritable bowel syndrome (IBS) [9, 16, 18]. However, the few microbiome studies on this organism have indicated that Blastocystis is a common commensal in the human gut and is associated with increased bacterial diversity [6].

Based on sequence analysis of the small subunit ribosomal (SSU) RNA gene, at least 22 subtypes of Blastocystis have been identified in animals and humans worldwide [31]. Subtypes ST1-10, ST12, and ST14 have been found in humans with varying prevalence, but ST1-4 are the most common, accounting for more than $90 \%$ of human Blastocystis infections $[20,26,33]$. Accumulating evidence has shown that the same subtype of Blastocystis can colonize a wide range of hosts, implying that these subtypes lack host-specific features.

In China, Blastocystis has been found in humans and both domestic and captive wildlife animals belonging to the orders Carnivora, Artiodactyla, Perissodactyla, Rodentia, and primates [10, 13-15, 37, 43], highlighting these animals as potential hosts for human infection with Blastocystis. However, limited studies have been conducted in which Blastocystis has been isolated from wild animals in China, and their role as a reservoir of infection for humans and other animals remains unknown.

Sichuan Wolong National Natural Reserve is the third largest nature reserve in China, covering an area of 200,000 ha. The area is known for its complex natural conditions and is inhabited by the largest number of rare animals in Sichuan Province (https://baike.so.com/doc/5376249-5612365.html). The connection with the outside world via the development of tourism means that the chances of contact between animals and humans in the reserve have greatly increased, heightening the risk of zoonotic transmission. Therefore, the purpose of this study was to investigate the prevalence and subtypes of Blastocystis in the wild animals of this reserve and to assess the zoonotic potential of the Blastocystis colonizing these animals.

\section{Materials and methods}

\section{Ethical statement}

This study was performed in accordance with the recommendations of the Guide for the Care and Use of Laboratory Animals of the Ministry of Health, China. Only fecal samples collected after spontaneous defecation of the wild animals were analyzed. Consequently, this study did not require full Animal Ethics Committee approval, in accordance with Chinese law. No animals were harmed during the sampling process. Permission was obtained from reserve managers prior to collection of fecal specimens.

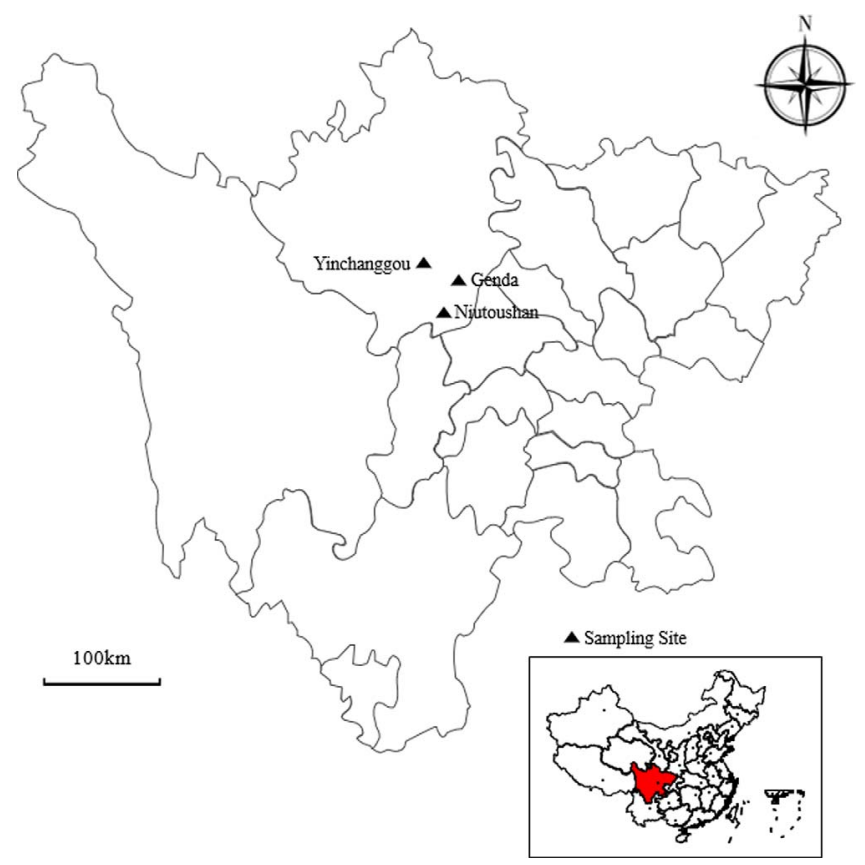

Figure 1. Geographical distribution of the sampled sites (filled triangle) in Sichuan Province, Southwestern China.

\section{Sample collection}

A total of 300 fecal samples was collected from three areas within the Sichuan Wolong National Natural Reserve (Fig. 1) between March 2020 and December 2020, with 127 samples collected in Genda, 93 in Yinchanggou, and 80 in Niutoushan (Tables 1 and 2). All fecal samples were collected by experienced mountain patrol staff of the Sichuan Wolong National Natural Reserve during patrols and strict controls were implemented to minimize potential contamination between samples from different animal species. Camouflaged video equipment was placed to identify the species of animal prior to sampling, based on its range or nesting location. Briefly, stool samples were collected from tracks or in the vicinity of nests. The species from which a sample originated was inferred in the field according to the shape, size, and texture of the fecal sample, footprints, and the presence of nearby nests, and confirmed with video information. Some animal feces were collected immediately after the animal was observed to defecate, including Galliformes, primates, and some Artiodactyla. Fecal samples for which the species could not be identified or samples that were older than two days were not included. All fecal samples were collected in sterilized plastic containers using disposable sterile gloves and preserved at $4{ }^{\circ} \mathrm{C}$ until DNA extraction.

\section{DNA extraction}

All fecal specimens were sieved and washed three times with distilled water by centrifugation at $3000 \times g$ for $10 \mathrm{~min}$. Genomic DNA was extracted using a QIAamp DNA Stool Mini Kit (Qiagen, Hilden, Germany) from approximately $250 \mathrm{mg}$ of sample, according to the manufacturer's instructions. Both Blastocystis-positive and negative fecal sample controls 
Table 1. Factors associated with the prevalence of Blastocystis in wild animals in China.

\begin{tabular}{lcccc}
\hline Factor & No. positive/overall & Prevalence $(95 \% \mathrm{CI})$ & OR $(95 \% \mathrm{CI})$ & $p$ value \\
\hline Locations & & & & \\
$\quad$ Genda & $7 / 127$ & $5.5(1.5-9.5)$ & $3.8(1.5-9.7)$ & Reference \\
$\quad$ Yinchanggou & $17 / 93$ & $18.3(10.4-26.1)$ & $1.4(0.5-4.3)$ & 0.004 \\
$\quad$ Niutoushan & $6 / 80$ & $7.5(1.7-13.3)$ & & \\
Host & & & Reference & Reference \\
Rodentia & $1 / 7$ & $14.3(11.6-40.2)$ & $1.5(0.1-31.6)$ & 0.8 \\
Primates & $1 / 5$ & $20.0(15.1-55.1)$ & $0.9(0.1-7.8)$ & 0.9 \\
Artiodactyla & $26 / 198$ & $13.1(8.4-17.8)$ & $0.1(0.01-1.8)$ & 0.1 \\
Carnivora & $2 / 87$ & $2.3(0.9-5.4)$ & $0(0)$ & 1.0 \\
$\quad$ Galliformes & $0 / 3$ & 0.0 & & \\
Total & $30 / 300$ & $10.0(6.6-13.4)$ & &
\end{tabular}

Table 2. Animal samples collected from various hosts from three different areas in Sichuan Wolong National Nature reserve in Sichuan Province, southwestern China.

\begin{tabular}{|c|c|c|c|c|c|}
\hline Host & Scientific name & GD & $\mathrm{YC}$ & NT & No. of Blastocystis-positive/overall \\
\hline \multicolumn{6}{|l|}{ Primates } \\
\hline Tibetan macaque & Macaca thibetana & & 3 & & $0 / 3$ \\
\hline Snub-nosed monkey & Rhinopithecus roxellanae & 2 & & & $1 / 2$ \\
\hline \multicolumn{6}{|l|}{ Artiodactyla } \\
\hline Sambar & Rusa unicolor & 18 & 13 & 8 & $8 / 39$ \\
\hline Sika deer & Cervus nippon & & 14 & & $5 / 14$ \\
\hline Long-tailed goral & Naemorhedus griseus & & 15 & 2 & $5 / 17$ \\
\hline Crested deer & Elaphodus cephalophus & 2 & 4 & 2 & $4 / 8$ \\
\hline Chinese antelope & Capricornis milneedwardsii & 1 & 1 & 1 & $1 / 3$ \\
\hline Dwarf musk deer & Moschus berezovskii & 12 & 1 & 6 & $0 / 19$ \\
\hline Takin & Budorcas taxicolor & 15 & 9 & 1 & $0 / 25$ \\
\hline Blue sheep & Pseudois nayaur & 34 & & 8 & $3 / 42$ \\
\hline Tibetan antelope & Pantholops hodgsonii & & & 1 & $0 / 1$ \\
\hline Yak & Bos mutus & & & 15 & $0 / 15$ \\
\hline Gaur & Bos gaurus & 1 & & & $0 / 1$ \\
\hline Goral & Naemorhedus goral & 10 & & & $0 / 10$ \\
\hline Wild pig & Sus scrofa & 4 & & & $0 / 4$ \\
\hline \multicolumn{6}{|l|}{ Rodentia } \\
\hline Porcupine & Hystrix hodgsoni & 5 & 1 & 1 & $1 / 7$ \\
\hline \multicolumn{6}{|l|}{ Carnivora } \\
\hline Sand badger & Arctonyx collaris & & 2 & 1 & $1 / 3$ \\
\hline Lesser panda & Ailurus fulgens & 2 & 8 & & $0 / 10$ \\
\hline Leopard cat & Prionailurus bengalensis & 3 & 3 & 4 & $1 / 10$ \\
\hline Giant panda & Ailuropoda melanoleuca & 11 & 19 & 10 & $0 / 40$ \\
\hline Stone Marten & Martes foina & & & 2 & $0 / 2$ \\
\hline Swinhoe & Paguma larvata taivana & & & 1 & $0 / 1$ \\
\hline Asiatic black bear & Ursus thibetanus & & & 1 & $0 / 1$ \\
\hline Jackal & Cuon alpinus & 1 & & & $0 / 1$ \\
\hline Snow leopard & Panthera uncia & 6 & & 13 & $0 / 19$ \\
\hline \multicolumn{6}{|l|}{ Galliformes } \\
\hline Blood Pheasant & Ithaginis cruentus & & & 1 & $0 / 1$ \\
\hline Phasianus versicolor & Lophophorus lhuysii & & & 2 & $0 / 2$ \\
\hline Total & & 127 & 93 & 80 & $30 / 300$ \\
\hline
\end{tabular}

GD = Genda; YC = Yinchanggou; NT Niutoushan.

were included. The quality of the DNA was verified using NanoDrop (Thermo Fisher Scientific, Carlsbad, CA, USA) and the DNA was eluted in $50 \mu \mathrm{L}$ of nuclease-free water and stored at $-20{ }^{\circ} \mathrm{C}$ until PCR analysis.

\section{Polymerase chain reaction (PCR) amplification}

PCR amplification of the barcode region ( $600 \mathrm{bp})$ of the SSU rRNA gene was used to screen all DNA preparations for 
the presence of Blastocystis with the primers and cycling parameters previously described by Scicluna et al. [27]. The Taq PCR Master Mix (Sangon Biotech Co., Ltd., Shanghai, China) was used for all PCRs. Reagents used per $25 \mu \mathrm{L}$ reaction were as follows: $12.5 \mu \mathrm{L}$ Taq PCR Master Mix (Sangon Biotech Co., Ltd., Shanghai, China), $1 \mu \mathrm{L}$ of each primer $(0.4 \mu \mathrm{M}), 2 \mu \mathrm{L}$ of genomic DNA sample, $1.5 \mathrm{mM} \mathrm{MgCl}_{2}$, and nuclease-free water to the desired volume. All PCR tests were performed in triplicate, and both positive and negative controls were included. PCR products were subjected to $1.5 \%$ agarose gel electrophoresis (AddGene, Watertown, MA, USA) and visualized by staining with SYBR Safe DNA Gel Stain (Thermo Fisher Scientific).

\section{Nucleotide sequencing and analysis}

PCR products with the predicted size (approximately $600 \mathrm{bp}$ ) were excised from the agarose gel and purified using a QIAquick Gel Extraction Kit (Qiagen), according to the manufacturer's instructions. All PCR-positive products were bidirectionally sequenced on an ABI PRISMTM 3730 DNA Analyzer (Applied Biosystems, Foster City, CA, USA), using a BigDye Terminator v3.1 Cycle Sequencing kit (Applied Biosystems). The nucleotide sequences obtained were subjected to BLAST searches (http://www.ncbi.nlm.nih.gov/blast/) and then aligned and analyzed. Reference sequences were downloaded from the GenBank database using the program Clustal X 2.0 (http://www.clustal.org/) to determine the subtypes of the Blastocystis isolates. The representative nucleotide sequences generated were deposited in GenBank under the accession numbers MW404496, MW404497, MW404561, MW404583, MW404585, MW404588, and MW404590.

\section{Phylogenetic analysis}

To assess the genetic relationships of the Blastocystis genotypes in this study with sequences from GenBank that were identified in previous studies, phylogenetic analysis was performed by constructing a neighbor-joining tree using MEGA 6 software (http://www.megasoftware.net/). The evolutionary distances were calculated using the Kimura 2-parameter model. Undefined positions were removed from the alignment prior to phylogenetic analysis, and the alignment was trimmed using MEGA 6 (http://www.megasoftware.net/). The reliability of the trees was assessed by bootstrap analysis with 1000 replicates.

\section{Statistical analysis}

The prevalence of Blastocystis in the different study areas and the orders of animals infected were analyzed with the binary logit model using SPSS 22 (https://www.ibm.com/analytics/ spss-statistics-software). Each of these variables was included in the binary logit model as an independent variable via multivariable regression analysis. The results were considered statistically significant when the $p$-value was $<0.05$. The adjusted odds ratio (OR) and $95 \%$ confidence interval (CI) for each variable were calculated using binary logistic regression, and all risk factors were entered simultaneously.

\section{Results \\ Prevalence of Blastocystis in wild animals}

In the present study, 30 of the 300 fecal samples (10.0\%) collected from three areas of Sichuan Wolong National Natural Reserve, southwestern China, were determined to be Blastocystis-positive by PCR amplification of the barcode region of the SSU rRNA gene. The highest prevalence of Blastocystis was observed in Yinchanggou, followed by Niutoushan and Genda (Table 1). The difference in Blastocystis prevalence was significant in the three areas $(p<0.05)$. However, the difference in Blastocystis prevalence among animals of different orders was not significant $(p>0.05)$.

Overall, of the 27 species tested in this study, $10(37.0 \%)$ were positive for Blastocystis (Table 2). Of the 16 species tested in Genda, 4 (25.0\%) were positive for Blastocystis. The prevalence of the parasite was $53.8 \%$ (7/13) in Yinchanggou and $21.1 \%(4 / 19)$ in Niutoushan.

\section{Subtype distributions of Blastocystis in wild animals}

Five subtypes of Blastocystis were identified among the 30 positive samples, including three potentially zoonotic STs (ST1, ST3, and ST5) and two animal-specific STs (ST13 and ST14). ST13 (10/30) and ST14 (10/30) were the dominant subtypes found in the wild animals examined (Table 3), followed by ST1 (6/30), ST5 (3/30), and ST3 (1/30).

\section{Genetic characteristics of Blastocystis subtypes}

Identity analysis of the SSU rRNA gene revealed six sequences of ST1 isolate in sika deer, long-tailed goral, and porcupine that were identical to those found in chimpanzees from Tanzania: Rubondo Island (HQ286905). Similarly, one ST3 sequence found in sika deer showed $100 \%$ identity with the GenBank sequence MW242639 (from the red-bellied tree squirrel in China), and three ST5 sequences had 100\% similarity with that of sheep in China: Heilongjiang (MF974615).

Ten ST13 isolates contained two representative sequences. The sequence MW404585, which was found in ST13 isolates obtained from long-tailed goral, crested deer, and blue sheep, showed $99.43 \%$ similarity with a ST13 sequence that was isolated from a reindeer in China (MH325366), with only three nucleotide substitutions. The remaining sequence, MW404588, which was obtained from sambar and long-tailed goral, showed $100 \%$ similarity with an ST13 sequence MF186700 from a muntjac. Similarly, two representative sequences were also obtained in 10 of the ST14 isolates. The sequences MW404561 (obtained from sambar, Chinese antelope, and sand badger) and MW404583 (obtained from sambar, crested deer, blue sheep, and leopard cat) showed $99.42 \%$ identity with an ST14 sequence that was previously isolated from a sheep in the Czech Republic (MT039559) and 99.81\% similarity with 
Table 3. Prevalence of Blastocystis among different species.

\begin{tabular}{|c|c|c|c|c|}
\hline Species & $\begin{array}{l}\text { Prevalence (No. of } \\
\text { positive/overall) }\end{array}$ & GD & $\mathrm{YC}$ & NT \\
\hline Snub-nosed monkey & $50.0(1 / 2)$ & ST5 (1) & & \\
\hline Sambar & $20.5(8 / 39)$ & ST13 (3) & ST14 (3) & ST14 (2) \\
\hline Sika deer & $35.7(5 / 14)$ & & ST1 (4); ST3 (1) & \\
\hline Long-tailed goral & $29.4(5 / 17)$ & & ST1 (1); ST5 (2); ST13 (2) & \\
\hline Crested deer & $50.0(4 / 8)$ & ST13 (1) & $\mathrm{ST} 13(1)$ & $\operatorname{ST} 13(1) ; \operatorname{ST} 14(1)$ \\
\hline Chinese antelope & $33.3(1 / 3)$ & & ST14 (1) & \\
\hline Blue sheep & $7.1(3 / 42)$ & ST13 (2) & & ST14 (1) \\
\hline Porcupine & $14.3(1 / 7)$ & & ST1 (1) & \\
\hline Sand badger & $33.3(1 / 3)$ & & & ST14 (1) \\
\hline Leopard cat & $10.0(1 / 10)$ & & ST14 (1) & \\
\hline Total & $20.7(30 / 145)$ & ST5 (1); ST13 (6) & ST1 (6); ST3 (1); ST5 (2); ST13 (3); ST14 (5) & ST13 (1); ST14 (5) \\
\hline
\end{tabular}

GD = Genda $;$ YC $=$ Yinchanggou $;$ NT $=$ Niutoushan.

that of an isolate from sika deer in China (MK357783), with three and one nucleotide substitutions, respectively.

\section{Phylogenetic analysis of Blastocystis}

Seven representative sequences were obtained from the 30 Blastocystis isolates in this study. These sequences showed high identity with reference sequences for Blastocystis in GenBank. Newly acquired sequences belonged to ST1, ST3, ST5, ST13, and ST14. ST1 clustered with sequences from humans from the Philippines, Russia, and China. ST3 can be grouped with sequences that are mainly from humans in Brazil and dogs in China. ST5 clustered with sequences from sheep in China and pigs in Germany, while ST13 can be grouped with sequences isolated from reindeer muntjac and sambar. ST14 forms a clade with sequences from cattle, sheep, and goats (Fig. 2).

\section{Discussion}

Blastocystis is the most frequent parasite reported in humans and several other animals with controversial pathogenicity [24, 41]. Previous studies have linked infection with Blastocystis to nutritional and gastrointestinal disorders in both developing and developed countries [28]. However, recent microbiome studies have reported that Blastocystis may be an indicator of good intestinal health [5]. Zoonotic STs are occasionally transmitted between animals and humans, and some animals may be significant potential reservoirs for human infection [22, 29, 44].

Epidemiological studies have been conducted in domestic animals, including pigs, cattle, sheep, and goats, but only a few reports on captive wildlife have been documented in China [13]. The prevalence of Blastocystis in the wild animals examined in this study was $10.0 \%$ (30/300); this is lower than that previously found in zoo animals in Western Australia (42\%, 32/76) [25], wild animals on Qinling Mountains, China $(40.2 \%, 200 / 497)$ [42], zoo animals in Japan $(39.0 \%, 46 / 118)$ [2], wild animals in Brazil $(34.4 \%, 115 / 334)$ [35], zoo animals in the United Kingdom $(34.2 \%, 79 / 231)$, various captive animals in France $(32.2 \%, 99 / 307)$ [12], captive wildlife in four zoos of southwestern China $(15.7 \%, 66 / 420)$ [15], and captive mammalian wildlife in Bangladesh National Zoo (15.5\%, $31 / 200$ ) [29]. However, the prevalence is higher than that observed in animals from three city zoos in China (6.0\%, 27/450) [23]. At this time, it is unclear how factors such as the conditions in which animals are housed, the animal species sampled, the number of samples examined, and management methods affect the prevalence, both in different countries and in the same country.

The Blastocystis prevalence of $20.0 \%$ found in non-human primates (NHPs) was higher than that in rodents $(14.3 \%)$, Artiodactyla (13.1\%), Carnivora (2.3\%), and Galliformes $(0.0 \%)$. However, the small number of positive samples meant that the differences observed between these groups were not significant. Five Blastocystis STs, including ST1, ST3, ST5, ST13, and ST14, were identified in 30 Blastocystis-positive samples from four orders of wildlife (Tables 2 and 3). These STs have also been documented in European [8, 12, 27, 32] and Brazilian primates [35], while ST4, ST5, and ST8 have previously been found in monkeys [27, 32, 35, 40]. The sequences obtained from primates in this study belonged to ST5, infecting the snub-nosed monkey. ST5 has also been found sporadically in humans that are in close contact with animals, suggesting zoonotic transmission [30, 39].

Previous studies have confirmed the presence of other STs such as ST1-3, ST5, ST7, ST8, ST10, and ST17 in rodents $[4,7]$. In this study, ST1 was identified in rodents (porcupine), corroborating the previous data. The infection of Wistar rats with ST1 has been reported to lead to moderate and severe pathological changes, indicating the potential pathogenicity of this subtype [17].

Five subtypes (ST1, ST3, ST5, ST13, and ST14) were identified in Artiodactyla (long-tailed goral, sika deer, sambar, crested deer, Chinese antelope, and blue sheep). Previous studies have reported that many animals in the order Artiodactyla harbor Blastocystis, including cattle, pigs, sheep, deer, and goats $[13,19]$. To date, most STs, including ST1, ST3, ST5, ST13, and ST14, have been identified in Artiodactyla [4, 38]. 


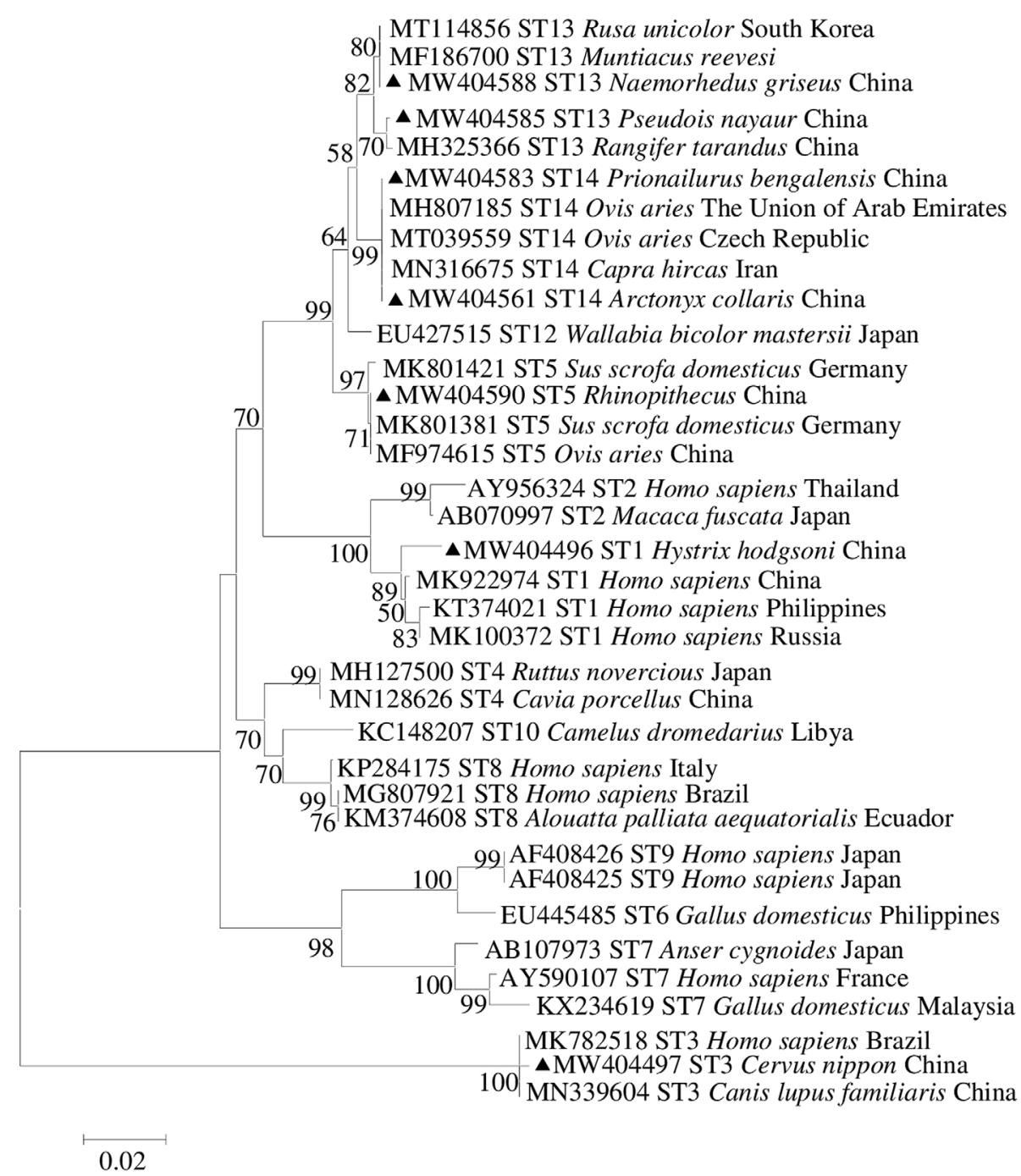

Figure 2. Phylogenetic relationships among nucleotide sequences of Blastocystis partial small subunit ribosomal RNA (SSU rRNA) genes. The neighbor-joining method was used to construct the trees by the Kimura-2-parameter model. The numbers on the branches are percent bootstrapping values from 1000 replicates, with values of more than 50\% shown in the tree. Each sequence is identified by its accession number, subtypes, host origin, and country. Genotypes marked with black triangles are known genotypes identified in this study, respectively.

In this study, ST1 was found in sika deer and long-tailed goral, ST3 was identified in sika deer, ST5 was found in long-tailed goral, ST13 was found in sambar, long-tailed goral, crested deer, and blue sheep, and ST14 was identified in sambar, crested deer, Chinese antelope, and blue sheep. Many previous surveys have indicated that ST1 and ST3 are the two most common subtypes infecting humans in several countries [1, 3]. This study has identified the potential for transmission of Blastocystis infection between humans and Artiodactyla. Therefore, the role of Artiodactyla in transmitting these subtypes should be further evaluated in future studies. ST5 has been identified in various animals, such as cattle, sheep, NHPs, and birds [19]. Surprisingly, ST13 was also determined in Java mouse-deer in France [12] and in a mouse deer in the United Kingdom [4]. Meanwhile, sheep in China [21] and muntjac deer in the United Kingdom have also been found to be infected with ST14 [7].

The sequences obtained from Carnivora in this study belonged to ST14 with the isolates infecting sand badgers and leopard cats. ST14 is often reported in artiodactyls but is almost absent in Carnivora [7].

\section{Conclusions}

To the best of our knowledge, this is the first molecular investigation in which Blastocystis infection has been observed in sambar, long-tailed goral, crested deer, Chinese antelope, blue sheep, sand badger, and leopard cat in China, further broadening the host range of Blastocystis [11]. The prevalence of Blastocystis was $10.0 \%$ (30/300) in the wild animals of southwestern China, with five Blastocystis subtypes (ST1, ST3, ST5, ST13, and ST14) identified in this study. ST1, ST3, and ST5 are considered zoonotic subtypes, suggesting that these wild animals may serve as natural reservoirs for human Blastocystis infection. The findings of the present study provide preliminary data for monitoring and investigating the transmission routes of Blastocystis. 


\section{Statement}

The study has been published as a preprint.

\section{Abbreviations}

STs Subtypes

PCR Polymerase chain reaction

SSU rRNA Small subunit ribosomal RNA

IBD Inflammatory bowel disease

IBS Irritable bowel syndrome

ORs Odds ratios

NHPs Nonhuman primates

Acknowledgements. We would like to thank the staff of the Funding Agency for their great contribution to sample collection.

\section{Authors' contributions}

This study was conceived and designed by GP. Experiments were performed by SC, WM, TH, ZZ (Ziyao Zhou), and LD. Fecal samples were collected by XS, YC, HL, YC, ZZ (Zhijun Zhong), and HF. Data were analyzed by LS and KZ. All authors have read and approved the submitted version of this manuscript.

\section{Funding}

This work was funded by the Special Fund for Forestry Reform and Development of Wolong Special Administrative Region of Sichuan Province (510000-02-064387).

\section{Availability of data and materials}

The nucleotide sequences generated in the present study have been deposited in GenBank (https://www.ncbi.nlm.nih. gov/) under accession numbers MW404496, MW404497, MW404561, MW404583, MW404585, MW404588, and MW404590. The datasets used and/or analyzed during the current study are available from the corresponding author on reasonable request.

\section{Competing interests}

The authors declare that they have no competing interests

\section{References}

1. Abdulsalam AM, Ithoi I, Al-Mekhlafi HM, Al-Mekhlafi AM, Ahmed A, Surin J. 2013. Subtype distribution of Blastocystis isolates in Sebha, Libya. PLoS One, 8(12), e84372.

2. Abe N, Nagoshi M, Takami K, Sawano Y, Yoshikawa H. 2002. A survey of Blastocystis sp. in livestock, pets, and zoo animals in Japan. Veterinary Parasitology, 106(3), 203-212.
3. Alfellani MA, Stensvold CR, Vidal-Lapiedra A, Onuoha ES, Fagbenro-Beyioku AF, Clark CG. 2013. Variable geographic distribution of Blastocystis subtypes and its potential implications. Acta Tropica, 126(1), 11-18.

4. Alfellani MA, Taner-Mulla D, Jacob AS, Imeede CA, Yoshikawa H, Stensvold CR, Clark CG. 2013. Genetic diversity of blastocystis in livestock and zoo animals. Protist, 164(4), 497-509.

5. Andersen LO, Stensvold CR. 2016. Blastocystis in health and disease: are we moving from a clinical to a public health perspective? Journal of Clinical Microbiology, 54(3), 524-528.

6. Beghini F, Pasolli E, Truong TD, Putignani L, Cacciò SM, Segata N. 2017. Large-scale comparative metagenomics of Blastocystis, a common member of the human gut microbiome. ISME Journal, 11(12), 2848-2863.

7. Betts EL, Gentekaki E, Thomasz A, Breakell V, Carpenter AI, Tsaousis AD. 2018. Genetic diversity of Blastocystis in nonprimate animals. Parasitology, 145(9), 1228-1234.

8. Betts EL, Gentekaki E, Tsaousis AD. 2020. Exploring microeukaryotic diversity in the gut: co-occurrence of Blastocystis subtypes and other protists in zoo animals. Frontiers in Microbiology, 11, 288.

9. Boorom KF, Smith H, Nimri L, Viscogliosi E, Spanakos G, Parkar U, Li LH, Zhou XN, Ok UZ, Leelayoova S, Jones MS. 2008. Oh my aching gut: irritable bowel syndrome, Blastocystis, and asymptomatic infection. Parasites \& Vectors, 1(1), 40.

10. Chai Y, Deng L, Liu H, Yao J, Zhong Z, Fu H, Shen L, Zhou Z, Deng J, Hu Y, Peng G. 2020. First subtyping of Blastocystis sp. from pet rodents in southwestern China. International Journal for Parasitology: Parasites and Wildlife, 11, 143-148.

11. Chen S, Meng W, Zhou Z, Deng L, Shi X, Chai Y, Liu H, Cheng Y, Zhong Z, Fu H, Shen L, Zhang K, He T, Peng G. 2021. Genetic characterization of Blastocystis from wild animals in Sichuan Wolong National Natural Reserve, southwestern of China-Zoonotic potential. PREPRINT (Version 2) available at Research Square. https://doi.org/10.21203/rs.3.rs-471433/v2.

12. Cian A, El Safadi D, Osman M, Moriniere R, Gantois N, Benamrouz-Vanneste S, Delgado-Viscogliosi P, Guyot K, Li LL, Monchy S, Noël C, Poirier P, Nourrisson C, Wawrzyniak I, Delbac F, Bosc S, Chabé M, Petit T, Certad G, Viscogliosi E. 2017. Molecular epidemiology of Blastocystis sp. in various animal groups from two French Zoos and evaluation of potential zoonotic risk. PloS One, 12(1), e169659.

13. Deng L, Chai Y, Zhou Z, Liu H, Zhong Z, Hu Y, Fu H, Yue C, Peng G. 2019. Epidemiology of Blastocystis sp. infection in China: a systematic review. Parasite, 26, 41.

14. Deng L, Yao JX, Liu HF, Zhou ZY, Chai YJ, Wang WY, Zhong ZJ, Deng JL, Ren ZH, Fu HL, Yan X, Yue CJ, Peng GN. 2019. First report of Blastocystis in giant pandas, red pandas, and various bird species in Sichuan province, southwestern China. International Journal for Parasitology: Parasites and Wildlife, 9, 298-304.

15. Deng L, Yao J, Chen S, He T, Chai Y, Zhou Z, Shi X, Liu H, Zhong Z, Fu H, Peng G. 2021. First identification and molecular subtyping of Blastocystis sp. in zoo animals in southwestern China. Parasites \& Vectors, 14(1), 11.

16. Dogruman-Al F, Kustimur S, Yoshikawa H, Tuncer C, Simsek Z, Tanyuksel M, Araz E, Boorom K. 2009. Blastocystis subtypes in irritable bowel syndrome and inflammatory bowel disease in Ankara, Turkey. Memorias do Instituto Oswaldo Cruz, 104(5), 724-727.

17. Hussein EM, Hussein AM, Eida MM, Atwa MM. 2008. Pathophysiological variability of different genotypes of human Blastocystis hominis Egyptian isolates in experimentally infected rats. Parasitology Research, 102(5), 853-860. 
18. Jimenez-Gonzalez DE, Martinez-Flores WA, Reyes-Gordillo J, Ramirez-Miranda ME, Arroyo-Escalante S, Romero-Valdovinos M, Stark D, Souza-Saldivar V, Martinez-Hernandez F, Flisser A, Olivo-Diaz A, Maravilla P. 2012. Blastocystis infection is associated with irritable bowel syndrome in a Mexican patient population. Parasitology Research, 110(3), 1269-1275.

19. Jiménez PA, Jaimes JE, Ramírez JD. 2019. A summary of Blastocystis subtypes in North and South America. Parasites \& Vectors, 12(1), 376.

20. Khaled S, Gantois N, Ly AT, Senghor S, Even G, Dautel E, Dejager R, Sawant M, Baydoun M, Benamrouz-Vanneste S, Chabé M, Ndiaye S, Schacht AM, Certad G, Riveau G, Viscogliosi E. 2020. Prevalence and subtype distribution of Blastocystis sp. in Senegalese school children. Microorganisms, 8(9), 1408.

21. Li WC, Wang K, Gu Y. 2018. Occurrence of Blastocystis sp. and Pentatrichomonas hominis in sheep and goats in China. Parasites \& Vectors, 11(1), 93.

22. Li J, Karim MR, Li D, Rahaman Sumon SMM, Siddiki SHMF, Rume FI, Sun R, Jia Y, Zhang L. 2019. Molecular characterization of Blastocystis sp. in captive wildlife in Bangladesh National Zoo: Non-human primates with high prevalence and zoonotic significance. International Journal for Parasitology: Parasites and Wildlife, 10, 314-320.

23. Li XD, Zou Y, Pan J, Liang QL, Zeng Z, Meng YM, Wang XL, Wang HN, Zhu XQ. 2020. Prevalence and subtypes of Blastocystis sp. infection in zoo animals in three cities in China. Parasitology Research, 119(2), 465-471.

24. Meloni D, Sanciu G, Poirier P, El Alaoui H, Chabé M, Delhaes L, Dei-Cas E, Delbac F, Luigi Fiori P, Di Cave D, Viscogliosi E. 2011. Molecular subtyping of Blastocystis sp. isolates from symptomatic patients in Italy. Parasitology Research, 109(3), 613-619.

25. Parkar U, Traub RJ, Vitali S, Elliot A, Levecke B, Robertson I, Geurden T, Steele J, Drake B, Thompson RC. 2010. Molecular characterization of Blastocystis isolates from zoo animals and their animal-keepers. Veterinary Parasitology, 169(1-2), 8-17.

26. Ramírez JD, Sánchez A, Hernández C, Flórez C, Bernal MC, Giraldo JC, Reyes P, López MC, García L, Cooper PJ, Vicuña Y, Mongi F, Casero RD. 2016. Geographic distribution of human Blastocystis subtypes in South America. Infection, Genetics and Evolution, 41, 32-35.

27. Scicluna SM, Tawari B, Clark CG. 2006. DNA barcoding of blastocystis. Protist, 157(1), 77-85.

28. Seguí R, Muñoz-Antoli C, Klisiowicz DR, Oishi CY, Köster PC, de Lucio A, Hernández-de-Mingo M, Puente P, Toledo R, Esteban JG, Carmena D. 2018. Prevalence of intestinal parasites, with emphasis on the molecular epidemiology of Giardia duodenalis and Blastocystis sp., in the Paranagua Bay, Brazil: a community survey. Parasites \& Vectors, 11(1), 490.

29. Sharifi Y, Abbasi F, Shahabi S, Zaraei A, Mikaeili F, Sarkari B. 2020. Comparative genotyping of Blastocystis infecting cattle and human in the south of Iran. Comparative Immunology, Microbiology and Infectious Diseases, 72, 101529.

30. Stensvold CR, Clark CG. 2016. Current status of Blastocystis: a personal view. Parasitology International 65(6 Pt B), 763-771.
31. Stensvold CR, Clark CG. 2020. Pre-empting Pandora's Box: Blastocystis subtypes revisited. Trends in Parasitology, 36(3), 229-232.

32. Stensvold CR, Alfellani MA, Nørskov-Lauritsen S, Prip K, Victory EL, Maddox C, Nielsen HV, Clark CG. 2009. Subtype distribution of Blastocystis isolates from synanthropic and zoo animals and identification of a new subtype. International Journal for Parasitology, 39(4), 473-479.

33. Stensvold CR, Tan KSW, Clark CG. 2020. Blastocystis. Trends in Parasitology, 36(3), 315-316.

34. Torgerson PR, Devleesschauwer B, Praet N, Speybroeck N, Willingham AL, Kasuga F, Rokni MB, Zhou XN, Fèvre EM, Sripa B, Gargouri N, Fürst T, Budke CM, Carabin H, Kirk MD, Angulo FJ, Havelaar A, de Silva N. 2015. World Health Organization estimates of the global and regional disease burden of 11 foodborne parasitic diseases, 2010: a data synthesis. PLoS Medicine, 12(12), e1001920.

35. Valença-Barbosa C, do Bomfim TCB, Teixeira BR, Gentile R, Neto SFDC, Magalhães BSN, Balthazar DA, da Silva FA, Biot R, d'Avila Levy CM, Santos HLC. 2019. Molecular epidemiology of Blastocystis isolated from animals in the state of Rio de Janeiro, Brazil. PloS One, 14(1), e210740.

36. Wang $\mathrm{W}$, Owen $\mathrm{H}$, Traub RJ, Cuttell L, Inpankaew $\mathrm{T}$, Bielefeldt-Ohmann H. 2014. Molecular epidemiology of Blastocystis in pigs and their in-contact humans in Southeast Queensland, Australia, and Cambodia. Veterinary Parasitology, 203(3-4), 264-269.

37. Wang J, Gong B, Yang F, Zhang W, Zheng Y, Liu A. 2018. Subtype distribution and genetic characterizations of Blastocystis in pigs, cattle, sheep and goats in northeastern China's Heilongjiang Province. Infection, Genetics and Evolution, 57, 171-176.

38. Wawrzyniak I, Poirier P, Viscogliosi E, Dionigia M, Texier C, Delbac F, Alaoui HE. 2013. Blastocystis, an unrecognized parasite: an overview of pathogenesis and diagnosis. Therapeutic Advances in Infectious Disease, 1(5), 167-178.

39. Yan Y, Su S, Ye J, Lai X, Lai R, Liao H, Chen G, Zhang R, Hou Z, Luo X. 2007. Blastocystis sp. subtype 5: a possibly zoonotic genotype. Parasitology Research, 101(6), 1527-1532.

40. Yoshikawa H, Abe N, Wu Z. 2004. PCR-based identification of zoonotic isolates of Blastocystis from mammals and birds. Microbiology, 150(Pt 5), 1147-1151.

41. Yoshikawa H, Dogruman-Al F, Turk S, Kustimur S, Balaban N, Sultan N. 2011. Evaluation of DNA extraction kits for molecular diagnosis of human Blastocystis subtypes from fecal samples. Parasitology Research, 109(4), 1045-1050.

42. Zhao GH, Hu XF, Liu TL, Hu RS, Yu ZQ, Yang WB, Wu YL, Yu SK, Song JK. 2017. Molecular characterization of Blastocystis sp. in captive wild animals in Qinling Mountains. Parasitology Research, 116(8), 2327-2333.

43. Zhu W, Tao W, Gong B, Yang H, Li Y, Song M, Lu Y, Li W. 2017. First report of Blastocystis infections in cattle in China. Veterinary Parasitology, 246, 38-42.

44. Zhu W, Wei Z, Li Q, Lin Y, Yang H, Li W. 2020. Prevalence and subtype diversity of Blastocystis in human and nonhuman primates in North China. Parasitology Research, 119(8), 2719-2725.

Cite this article as: Chen S, Meng W, Zhou Z, Deng L, Shi X, Chai Y, Liu H, Cheng Y, Zhong Z, Fu H, Shen L, Zhang K, He T \& Peng G. 2021. Genetic characterization and zoonotic potential of Blastocystis from wild animals in Sichuan Wolong National Natural Reserve, Southwest China. Parasite 28, 73. 
An international open-access, peer-reviewed, online journal publishing high quality papers on all aspects of human and animal parasitology

Reviews, articles and short notes may be submitted. Fields include, but are not limited to: general, medical and veterinary parasitology; morphology, including ultrastructure; parasite systematics, including entomology, acarology, helminthology and protistology, and molecular analyses; molecular biology and biochemistry; immunology of parasitic diseases; host-parasite relationships; ecology and life history of parasites; epidemiology; therapeutics; new diagnostic tools.

All papers in Parasite are published in English. Manuscripts should have a broad interest and must not have been published or submitted elsewhere. No limit is imposed on the length of manuscripts.

Parasite (open-access) continues Parasite (print and online editions, 1994-2012) and Annales de Parasitologie Humaine et Comparée (1923-1993) and is the official journal of the Société Française de Parasitologie. 